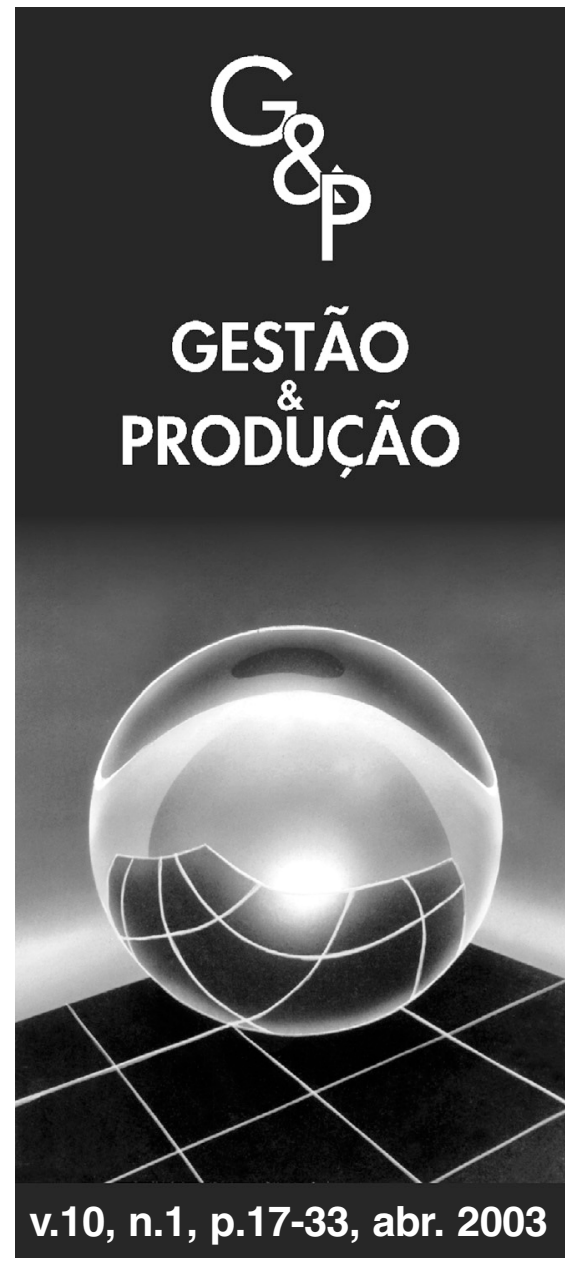

\title{
COMPETÊNCIAS ESSENCIAIS PARA MELHORIA CONTÍNUA DA PRODUÇÃO: ESTUDO DE CASO EM EMPRESAS DA INDÚSTRIA DE AUTOPEÇAS
}

\author{
Melissa Mesquita \\ Arvin Meritor, LVS Wheels Division, \\ Av. Major José Levy Sobrinho, 2700, CEP 13486-925, \\ Limeira, SP, e-mail: melissa.mesquita @arvinmeritor.com \\ Dário Henrique Alliprandini \\ Departamento de Engenharia de Produção, \\ Universidade Federal de São Carlos, \\ Via Washington Luís, $\mathrm{km} 235$, \\ CEP 13565-905, São Carlos, SP, \\ e-mail: dha@power.ufscar.br
}

\section{Resumo}

Este artigo apresenta os resultados de uma pesquisa descritiva e exploratória realizada em três empresas da indústria de autopeças, certificadas com ISO 9000 e QS 9000, a fim de identificar competências essenciais para melhoria contínua da produção. As principais observações encontradas foram: as empresas há muito vêm estruturando uma sistemática e desenvolvendo o treinamento em técnicas e ferramentas necessárias, considerando-se, assim, habilitadas a executar atividades de melhoria. Entretanto, elas não estão conduzindo atividades de melhoria contínua visando ao aumento de seu nível de maturidade, com foco no desenvolvimento de competências. Este artigo apresenta uma discussão sobre a importância da condução da gestão da melhoria contínua com base na gestão de competências, visando garantir o amadurecimento contínuo das atividades de melhoria contínua na organização.

Palavras-chave: melhoria contínua, gestão da produção, gestão do conhecimento, gestão da qualidade, gestão de competências. 


\section{Introdução}

$\mathrm{O}$ cuidado com as competências existentes na organização pode garantir que elas sejam vistas em sua totalidade e, se utilizadas na prática da melhoria contínua, levem ao aperfeiçoamento auto-sustentado e continuado dos processos da produção.

A melhoria da produção deve ser tratada de forma completa, o que requer balanceamento e integração dos sistemas técnicos e sociais. Isso conduz à necessidade de atuação em diferentes áreas e à consideração de aspectos como habilidades e motivação (Harrison, 2000); o que também pode ser confirmado nos trabalhos de Brannen et al. (1998) e Harrison \& Storey (1996).

É possível verificar, em várias empresas ou organizações, atividades de melhoria que muitas vezes são chamadas de "melhoria contínua", como, por exemplo, nas empresas com sistema de qualidade com base nos requisitos da QS 9000 . Entretanto, não se pode afirmar que essas atividades são realmente de melhoria contínua. Uma possível explicação seria o fato de elas ressaltarem a aplicação de técnicas e ferramentas sem entendimento básico dos comportamentos relacionados à cultura da empresa, os quais afetam o desempenho da atividade (Rodrigues, 1998).

Atualmente, é razoável admitir haver carência nas empresas quanto à coordenação das atividades de melhoria dentro de uma visão sistêmica dos processos existentes. As atividades normalmente focam a solução necessária para se adequar a um ou outro indicador de desempenho, e não estendem a análise para implicações em outros processos. Pode-se, então, esperar, como contribuição importante deste trabalho, o reconhecimento de alguns tipos de comportamentos que já são praticados nas empresas e que serviram de base ou alavanca para iniciar a estruturação de uma sistemática de melhoria contínua.

Assim, este artigo contribui para ampliar o escopo da coordenação das atividades de melhoria, que passa a ter consciência da importância de aspectos associados ao desenvolvimento de competências para a melhoria da produção. Afinal, o objetivo principal do estudo realizado foi identificar tais competências, sendo que o termo competência não foi relacionado ao indivíduo em si, mas abordado segundo o aspecto organizacional e de gestão das atividades de melhoria contínua da produção. Para isso, foram desenvolvidos os seguintes objetivos suplementares: caracterizar a sistemática de melhoria das empresas, incluindo técnicas, metodologias, abordagens utilizadas e capacitação; e identificar comportamentos relacionados às competências para melhoria contínua em empresas da indústria de autopeças.

Em razão de o trabalho ter seu foco nas atividades de melhoria, foram selecionadas empresas que já passaram pelo processo de implementação dos requisitos da QS 9000, pois estruturaram uma sistemática mínima para condução e coordenação das atividades de melhoria. Além disso, teve-se o cuidado de escolher as que já tinham prática em desenvolver atividades de melhoria da produção, principalmente para não limitar o escopo da pesquisa ao que a empresa realizou para atender ao requisito da norma em questão.

Além desta introdução, contextualizando o objetivo do estudo realizado, o artigo expõe alguns conceitos sobre melhoria contínua, seguidos de discussão sobre aspectos abstratos da melhoria contínua da produção, nesse caso, habilidades para melhoria contínua. A próxima seção trata de competência, de conhecimento e de sua relação com a melhoria contínua da produção. Em outra seção, é mostrado o método de pesquisa utilizado e, em seguida, a descrição e a discussão dos casos estudados. Por fim, são apresentados aspectos como a importância da melhoria contínua, a razão de melhorar continuamente, a importância da gestão das atividades de melhoria contínua, a identificação de uma nova habilidade básica e, em seguida, algumas considerações finais. 


\section{Compreendendo os conceitos e abordagens para melhoria contínua}

Primeiramente, é importante apresentar um conceito para melhoria contínua; para isso foi escolhida a definição utilizada por Caffyn \& Bessant (1996), por ser simples e ao mesmo tempo representar todo o seu escopo: "Melhoria contínua é um processo, em toda a empresa, focado na inovação incremental e contínua".

A obra de Slack et al. (1997) traz abordagem mais genérica, importante para contextualizar a melhoria contínua da produção em termos pragmáticos. Eles estabelecem passos a serem seguidos para chegar à melhoria. Na realidade, é o que acontece nas organizações: o desempenho é medido e acompanhado (com diferentes níveis de estruturação), e chega-se, então, aos pontos que merecem especial atenção e que precisam ser melhorados. Assim, escolhe-se melhoria contínua ou revolucionária (ou inovação), ou uma combinação das duas (nesse ponto já não há grande clareza por parte das organizações). Melhoria contínua e inovação são dois conceitos que, apesar de opostos, caminham juntos, pois são formas diferentes de tratar a melhoria de um padrão, não deixando de ser melhorias e, portanto, de haver a necessidade de serem analisadas conjuntamente.

Davenport (1994) trata especificamente da diferenciação entre melhoria contínua e inovação, aconselhando, assim como Juran (1969), a combinação das duas. Merli (1993) contextualiza a melhoria contínua na história do Japão, importante para enxergá-la como parte da cultura de uma organização, ou seja, a melhoria contínua não é eficaz se tratada isoladamente ou apenas como informação, precisa ser vivida.

Upton (1996) trata o tema melhoria contínua com enfoque mais prático para as organizações e apresenta passos que devem ser seguidos para efetivar essa melhoria, sendo menos genérico que Slack et al. (1997). Isso é importante para saber mais claramente onde a melhoria se aplica, como proceder e que recursos organizacionais usar, ajudando, assim, na contextualização das com- petências nas práticas das organizações, ou seja, é uma forma de identificar e desenvolver comportamentos para chegar às competências essenciais. Afinal, é na prática das atividades de melhoria contínua que se formam os comportamentos para adquirir algum tipo de competência essencial visando à melhoria contínua da produção.

Já Imai (1997) aborda especificamente a melhoria contínua, mostrando conceitos e sistemas associados a ela, o que facilita bastante sua identificação e desenvolvimento. Também estabelece uma comparação entre melhoria contínua e inovação.

Davenport (1994) também afirma que a participação nos programas de melhoria contínua da qualidade ocorre de baixo para cima no organograma organizacional, em que os funcionários são estimulados a examinar e recomendar mudanças nos processos de trabalho dos quais participam. Por outro lado, a reengenharia de processos, cuja abordagem é baseada na revisão e no reprojeto amplos dos processos de negócios de uma empresa, se dá muito mais de cima para baixo, pois exige administração forte da alta gerência, afinal, apenas os que estão em posições que controlam funções múltiplas podem ser capazes de reconhecer oportunidades de inovação. Obviamente, para que níveis organizacionais e operacionais tomem iniciativas para melhorar processos, a alta administração precisa estar comprometida com essa prática. Ou seja, Davenport não deixa de ter razão, afinal, todos na organização estão aptos a participarem de programas de melhoria contínua. Porém, assim como para a inovação, a melhoria contínua precisa do comprometimento da alta administração; sua alavanca não pode ficar apenas no nível operacional, também precisa estar alinhada estrategicamente e, assim, desdobrada de cima para baixo, caso contrário, tende a tornar-se um evento isolado. Isso pode ser evidenciado pelo estudo de caso realizado.

Shiba et al. (1997) também comparam rapidamente melhoria contínua e inovação, voltando-se para o operacional. Enfatizam bastante a gestão por processos, já citada por outros autores 
(“... os gerentes devem ser capazes de ver o processo de melhoria como um processo, com o propósito de proporcionar direção e apoio aos subordinados engajados nas atividades de melhoria"). Isso significa enxergar a melhoria como um processo. É esse processo que diferenciará uma empresa da outra, o como fazer, o como chegar às competências essenciais para melhoria contínua e os comportamentos particulares de cada uma visando chegar a um resultado comum: a competência essencial para melhoria contínua. Os autores consideram a melhoria um processo de resolução de problemas e, a partir daí, propõem um modelo para essa resolução, definindo três tipos de melhoria: controle de processos, melhoria reativa e melhoria proativa. $\mathrm{O}$ uso dessa terminologia auxilia bastante na identificação do nível de prática para melhoria contínua em que as organizações se encontram.

Outras abordagens também são importantes, como, por exemplo, os sistemas da qualidade ISO 9000 e QS 9000 - ambiente escolhido para a realização da pesquisa de campo -, o CEDAC (Cause and effect diagram with the addition of cards), o PDCA (o já conhecido ciclo Plan-docheck-action), as sete ferramentas da qualidade, o TQM (Total quality management), o CCQ (Círculos de controle da qualidade), o Seis Sigma e a metodologia Triz (Teoria da solução inventiva de problemas), pois dependendo de seu nível de prática, pode-se definir o grau de maturidade de uma empresa em relação à melhoria contínua. Também é relevante o fato de já haver uma nova norma para o setor automotivo, a ISO/TS 16949, que aborda a melhoria contínua dentro do requisito "Responsabilidade da Administração", uma evidência de que a melhoria contínua da produção tem de estar alinhada estrategicamente.

Finalmente, Bessant et al. (1994) apresentam a importância do gerenciamento das atividades de melhoria contínua, explicitando aspectos do gerenciamento, como objetivos, planejamento, comprometimento da alta gerência, etc., sendo de fundamental importância na investigação da sistemática de melhoria contínua nas empresas.

\section{Habilidades para melhoria contínua}

Neste item a melhoria contínua é voltada para aspectos mais abstratos das organizações, ou seja, são apresentadas apenas ferramentas para ampliar o foco, vislumbrando comportamentos, habilidades, competências, aprendizagem e conhecimento.

A Tabela 1 apresenta as habilidades e as normas comportamentais propostas por Caffin \& Bessant (1996). A primeira coluna mostra as habilidades básicas que uma organização deve apresentar para ser capaz de promover a boa prática da melhoria contínua. Relacionadas a cada uma das habilidades básicas, as normas comportamentais estão listadas na segunda coluna. Elas representam os padrões de comportamento que devem estar presentes na organização, a fim de que a empresa tenha a habilidade básica associada à norma comportamental. Mais adiante essa tabela é adaptada para os objetivos da pesquisa realizada (Tabela 2).

Caffin \& Bessant (1996), assim como os autores deste estudo, se depararam com a falta de clareza quando se tratava do tema melhoria contínua. Isso pode levar as empresas a se equivocarem no que diz respeito a sua implementação. Assim, nas análises que fizeram das várias implementações de melhoria contínua, conseguiram identificar as habilidades básicas e as normas comportamentais, constatando que nem todas as empresas que dizem praticar melhoria contínua realizam uma gestão que considera aspectos relacionados ao desenvolvimento de habilidades, ou seja, não somente aspectos técnicos e metodológicos.

Portanto, é importante analisar e gerir a prática da melhoria contínua da produção a partir de um ponto de vista diferente e mais abrangente do que o considerado "usual" (prática de uma sistemática preestabelecida para melhoria e solução de problemas, bem como para capacitação e uso de ferramentas apropriadas). Vale destacar que a melhoria contínua não deve ser desconectada das técnicas, afinal são elas que capacitam as empresas a desenvolver habilidades e comportamentos. 


\section{Tabela 1 - Habilidades básicas e normas comportamentais (Caffin \& Bessant, 1996).}

\section{Habilidades básicas}

\section{Normas comportamentais}

(A) Ligar as atividades de melhoria contínua em todos os níveis de estratégia da empresa.
1. Indivíduos e grupos usam metas e objetivos estratégicos da organização para focar e priorizar suas atividades de melhoria.

2. Sistema de melhoria contínua é constantemente monitorado e desenvolvido.

(B) Gerenciar estrategicamente o desenvolvimento do sistema de melhoria contínua nas estruturas da organização.

3. A avaliação progressiva assegura que a estrutura e a infra-estrutura da organização, bem como o sistema de melhoria contínua, consistentemente, reforcem e apóiem um ao outro.

4. Gerentes de todos os níveis mostram compromisso ativo e liderança em relação à melhoria contínua.

(C) Gerar envolvimento sustentado em inovação incremental.

5. Participação pró-ativa em melhoria incremental.

(D) Trabalhar efetivamente por meio das divisões internas e externas.

6. Trabalho efetivo de indivíduos e grupos por todos os níveis das divisões internas e externas.

7. Aprendizagem por intermédio de experiências próprias e de outros, tanto positivas como negativas.

(E) Garantir que a aprendizagem ocorra e seja capturada e compartilhada em todos os níveis.

8. A organização articula e desdobra a aprendizagem de indivíduos e grupos.

(F) Articular, demonstrar e comunicar os valores da melhoria contínua.
Assim, são estabelecidas fases de desenvolvimento ou maturidade para melhoria contínua (Caffin \& Bessant, 1996), o que contribui para a realização do estudo de caso; afinal, o que pode diferenciar uma empresa de outra é seu nível de prática - como desenvolve a melhoria contínua -, que não pode ser copiado. Tais níveis de maturidade também são importantes para guiar as empresas. Por meio deles é possível saber o patamar atual e onde se pode e se quer chegar, pelo levantamento de habilidades e comportamentos existentes e dos que se deseja obter. No desenvolvimento da melhoria contínua e do foco nas competências essenciais o importante é agir conscientemente em relação a cada passo dado e a ser dado. Dessa forma, a melhoria contínua, normalmente, vai se enraizando na rotina da empresa, passando a fazer parte de sua cultura. E é nesse ponto que se encontra a maior dificuldade das empresas; afinal, o rompimento de paradigmas culturais pode demorar bastante tempo.

As fases da estrutura de maturidade em melhoria contínua são (Caffin et al., 1997):

- Nível 1 (melhoria contínua natural): a organização não tem nenhuma das habilidades essenciais e nenhum dos comportamentos-chave está presente. Mas pode ter alguma atividade de melhoria, como a solução de problema que ocorre ao acaso. 
- Nível 2 (melhoria contínua formal): há mecanismos capacitadores alocados e evidência de que alguns aspectos dos comportamentos-chave estão começando a ser desempenhados conscientemente. Características comuns deste nível são: solução sistemática do problema, treinamento no uso de ferramentas simples de melhoria contínua e introdução de veículos apropriados para estimular o envolvimento.

- Nivel 3 (melhoria contínua dirigida para a meta): a organização está segura de suas habilidades e os comportamentos que as suportam se tornam norma. A solução de problema é direcionada para ajudar a empresa a atingir suas metas e objetivos, havendo monitoramento e sistemas de medição eficientes.

- Nível 4 (melhoria contínua autônoma): a melhoria contínua é amplamente autodirigida, com indivíduos e grupos fomentando atividades a qualquer momento que uma oportunidade aparece.

- Nível 5 (capacidade estratégica em melhoria contínua): a organização tem todo o conjunto de habilidades e todos os comportamentos que as reforçam tornam-se rotinas engrenadas. Muitas características atribuídas à "organização de aprendizado" estão presentes.

A organização muda ao longo dos níveis, construindo as habilidades básicas e desenvolvendo as normas comportamentais da melhoria contínua.

Também é de extrema importância o impacto das atividades de melhoria contínua no desempenho e na prática das organizações (Bessant et al., 2001), o que evidencia e redução de custos das empresas. Afinal, quando se trata de aspectos mais abstratos nas organizações, fica difícil visualizar seu impacto nos custos. Na realidade, em uma empresa tudo deve estar relacionado, pois a empresa é um todo e não pode ser tratada de forma fragmentada, toda ação realizada em certo lugar terá repercussão no restante. Aí está a importância de expandir a melhoria contínua e enxergá-la de forma sistêmica. Seu tratamento isolado tem vida curta.

\section{Conhecimento, competências e sua relação com melhoria contínua}

A questão "gestão de conhecimento" teve importante papel no desenvolvimento deste trabalho. Neste contexto, a questão das competências foi abordada para fundamentar a importância de sua gestão para melhoria contínua da produção. A correlação das competências essenciais com as habilidades básicas para melhoria contínua da produção foi realizada com base em Leonard-Barton (1995), assim como o conceito de competências focado no desenvolvimento de produto, adaptado para este trabalho. Essa correlação é importante para a visualização do gerenciamento estratégico da melhoria contínua e, conseqüentemente, de seu impacto na vantagem competitiva da organização. É importante notar que a autora foca habilidades individuais, não as habilidades organizacionais, tratadas no presente trabalho. O comportamento, apesar de ser visualizado em nível individual, também está associado às ações de um grupo de pessoas, ou seja, às ações presentes na organização como um todo.

A rigidez essencial, considerada por LeonardBarton (1995), é extremamente importante para atentarmos se as competências presentes em uma organização estão exercendo sua função (que é prover vantagem competitiva, ou seja, diferenciar uma empresa) ou se estão se comportando com rigidez essencial (causando desvantagens para a empresa) - aspecto importante a ser levado em consideração no momento em que as organizações fazem uma análise de seu status, identificando em que nível estão em relação à melhoria contínua. Assim, não basta levantar comportamentos e chegar às competências, é necessário identificar o papel dessas competências dentro das organizações e verificar se estão cumprindo seu propósito. 
Neste trabalho, a associação de habilidade básica e competência essencial garante o foco na questão do conhecimento organizacional.

A discussão sobre o desenvolvimento de uma proposta para gestão das atividades de melhoria contínua que levasse em consideração questões relacionadas às habilidades básicas e à gestão de competências surgiu a partir de algumas reflexões acerca das relações entre os elementos da melhoria contínua da produção e os tipos de competências escolhidos para o trabalho. A idéia iniciou-se pela associação de aspectos da melhoria contínua da produção com os três tipos de competências - suplementares, habilitadoras e essenciais - apresentados por Leonard-Barton (1995). Competências essenciais são aquelas que constituem uma fonte de vantagem competitiva para a empresa e que foram construídas ao longo do tempo e dificilmente são imitadas. Já as competências habilitadoras são necessárias, mas não suficientes para diferenciar a empresa de forma competitiva, são o mínimo para a empresa ser competitiva. As competências suplementares adicionam valor às competências essenciais, entretanto podem ser imitadas. Como o próprio nome sugere, é bom tê-las, porém não são essenciais. Tanto as competências habilitadoras como as suplementares não são suficientemente superiores para proporcionarem vantagem sustentável. A autora descreve a evolução da importância estratégica das competências tecnológicas, que se inicia com as competências suplementares, com menor importância estratégica, passa pelas competências habilitadoras e, finalmente, chega às competências essenciais, que são as mais importantes estrategicamente.

Neste artigo, procurou-se adaptar os tipos de competências identificados por Leonard-Barton (1995) para o caso específico da gestão da melhoria contínua. Pode-se notar, como segue, que a estratificação dos diversos aspectos da melhoria contínua nos três tipos de competências é bastante útil para facilitar o entendimento da complexidade das atividades de melhoria da produção.
Leonard-Barton (1995) trata as competências de forma sistêmica, englobando todas as atividades da empresa, principalmente o desenvolvimento de produto. Deseja-se aqui associar as competências às atividades de melhoria contínua da produção, ou seja, o foco está nas competências relacionadas à melhoria contínua da produção. Assim, como competências essenciais consideraram-se os comportamentos relacionados às habilidades básicas para melhoria contínua (veja Tabela 1), ou seja, o conjunto de habilidades básicas para melhoria contínua foi adotado como competências essenciais para melhoria contínua da produção

Na classificação de competências habilitadoras foram alocados os aspectos considerados mínimos para uma empresa iniciar atividades de melhoria, como, por exemplo, técnicas de solução de problemas, trabalho em grupo, etc.

Como competências suplementares foram incluídos os aspectos relacionados a práticas que possibilitam alavancar ou maximizar os benefícios das atividades de melhoria. Iniciativas particulares podem ser adicionadas à empresa a fim de ampliar, esclarecer e até aperfeiçoar as competências essenciais (neste caso, os comportamentos). Pode-se ter, por exemplo, a gerência por processos, um sistema da qualidade, um sistema de informação estruturado para qualidade, um sistema de custos da qualidade e o treinamento contínuo associado às iniciativas ou comportamentos afetados.

Dessa forma, pode-se dividir competências essenciais em dois tipos. O primeiro é o conhecimento específico do mercado/processo/produto, que não está explicitamente colocado por ser específico ou mesmo confidencial dentro de cada empresa. Outro tipo são as competências essenciais para atividades de melhoria contínua da produção, incluídas com base nas habilidades para melhoria contínua (Tabela 1). Obviamente, essa foi uma adequação aos propósitos deste trabalho, que aborda as competências para melhoria contínua da produção de maneira geral, não específica para empresa. Essa especificidade 
deve ser tratada por empresa, baseando-se na visão geral das competências essenciais, levando-se em consideração o ambiente e as competências essenciais de mercado/processo/ produto.

As competências essenciais para melhoria contínua da produção foram tratadas no levantamento de comportamentos que pudessem evidenciar a devida prática de atividades de melhoria. Tais comportamentos foram associados às habilidades básicas para melhoria contínua. As competências habilitadoras e suplementares foram associadas à sistematização das atividades de melhoria.

O conceito de competência essencial define que ela não pode ser copiada, no caso de produtos e processos isso fica muito claro. Entretanto, a associação feita no presente trabalho é diferente. Neste caso, as competências essenciais para melhoria contínua da produção são um objetivo que pode e deve ser copiado e seguido, porém, os comportamentos que levam a essas competências serão diferentes de uma empresa para outra. Ou seja, o que diferenciará uma empresa da outra é como chegar às competências.

Nonaka \& Takeuchi (1997) apresentam uma definição de conhecimento importante para a associação com as habilidades básicas ou competências essenciais. Afirmam que o conhecimento está em indivíduos, rotinas, processos, normas e práticas da organização, e a criação de conhecimento na empresa deve ser o cerne das estratégias de recursos humanos. Neste trabalho, o essencial das competências para melhoria contínua é o conhecimento arraigado na prática das atividades de melhoria contínua, ou seja, nos comportamentos que são capazes de diferenciar uma empresa de outra e, assim, proporcionar vantagem competitiva.

Davenport \& Prusak (1998) contextualizam a gestão do conhecimento, importante para esta pesquisa, na associação com a gestão de competências. Afinal, não basta possuir habilidades, é necessário gerenciá-las - o que não as desvin- cula do gerenciamento dos comportamentos de forma a proporcionarem vantagem competitiva para a empresa e não um conjunto de rigidez essencial.

O conhecimento está arraigado nos comportamentos e sua gestão pode servir de alavanca para a estruturação de um comportamento organizacional, levando naturalmente às habilidades básicas para melhoria contínua. Assim, a gestão do conhecimento leva aos comportamentos organizacionais; por sua vez, a presença dos comportamentos e sua boa gestão levam às competências essenciais e, por intermédio da gestão das competências essenciais, uma organização pode alcançar a vantagem competitiva. Afinal, o conhecimento arraigado nas atividades, nas normas, nas práticas, na experiência e nos valores pode suportar os comportamentos, caracterizando, assim, as normas comportamentais que levam às habilidades básicas para melhoria contínua da produção.

Esse referencial teórico serviu de base para a condução do estudo exploratório deste trabalho, permitindo ampliar a compreensão da prática da melhoria contínua nas empresas e, juntamente com os conceitos estudados na revisão teórica, construir um conjunto de considerações que podem ser bastante úteis para a gestão da melhoria contínua nas organizações.

\section{Método de pesquisa}

Com base nas características da pesquisa, seguiu-se os critérios: adequação aos conceitos, adequação aos objetivos, validade de construção, validade interna, validade externa e confiabilidade; a fim de selecionar a abordagem de pesquisa (Salomon, 1991; Bryman, 1989; Yin, 1989). Assim, entre as abordagens quali e quantitativa pôde-se concluir que a qualitativa foi a mais adequada para o desenvolvimento da presente pesquisa. Afinal, houve necessidade da presença do pesquisador, de captar e entender a interpretação e a opinião das pessoas, as 
variáveis eram difíceis de quantificar, houve contribuição para a teoria, necessidade de compreensão do uso da informação, conhecimento do sistema de gestão de competências, necessidade de identificar comportamentos organizacionais e de compreender os tipos de melhoria praticados, além da possibilidade de generalização da teoria.

Já o método de procedimento da pesquisa foi selecionado tendo por referência as características da pesquisa e a adequação dos métodos. Assim, considerando os métodos: pesquisa experimental, pesquisa de avaliação, estudo de caso e pesquisaação, foi possível concluir que o mais adequado às características da pesquisa desenvolvida foi o método de estudo de caso (presença do pesquisador, construção de teoria, variáveis difíceis de quantificar, responder à pergunta de pesquisa "como?" e dificuldade de manipulação das variáveis).

Utilizou-se a entrevista semi-estruturada como técnica para coleta de evidências. No nível macro, a unidade de análise foi um conjunto de empresas da indústria de autopeças, que preencheram os requisitos preestabelecidos para investigação e que estavam abertas à realização do estudo em sua estrutura organizacional. Já no nível micro, a unidade de análise foram as pessoas que participavam direta ou indiretamente das atividades de melhoria da produção.

\section{Descrição e discussão dos casos estudados}

Foram realizadas visitas em três empresas da indústria de autopeças (empresas A, B e C), nas quais foi aplicado um roteiro de pesquisa que contemplava questões relacionadas à sistematização das atividades de melhoria contínua da produção e às habilidades básicas para melhoria contínua da produção, tomando por base a Tabela 1, apresentada anteriormente. A escolha das empresas foi basicamente definida por dois critérios: a) ter o sistema da qualidade certificado pela ISO 9000, há pelo menos cinco anos, e QS 9000, há pelo menos um ano; e b) ter programas formais relacionados à melhoria contínua. A constatação desses critérios foi feita por meio de contato prévio com as empresas.

As três empresas são de grande porte, multinacionais e fornecedorass de primeiro nível na cadeia da indústria automotiva. A empresa "A" desenvolve e fabrica sistemas automotivos e os principais produtos são baterias e injeção eletrônica. Ela certificou-se nos requisitos QS 9000 em 1997 e já realizou três revisões em sua sistemática relacionada à melhoria contínua. A segunda empresa estudada, a empresa "B", também certificou-se nos requisitos QS 9000 em 1997 e já realizou cinco revisões nos procedimentos relacionados à melhoria contínua. Os principais produtos dessa empresa são transmissões para diversos tipos e porte de veículos automotores. A empresa "C" tem a certificação QS 9000 desde 1996 e as revisões das sistemáticas relacionadas à melhoria contínua são realizadas uma vez por ano. Essa empresa desenvolve e fabrica rodas de aço para automóveis e utilitários.

Cada uma dessas empresas apresenta programas específicos, e as habilidades relacionadas à melhoria contínua estão assinaladas nas últimas colunas da Tabela 2. Dentro de uma mesma empresa, os programas normalmente são diferentes, sendo que ao menos um é diretamente ligado ao chão-de-fábrica e outro apresenta características mais estratégicas que envolvem decisões gerenciais para a implementação das ações. Isso foi observado nas três empresas. A prática de atividades de melhoria sob a responsabilidade dos funcionários de chão-defábrica é advinda das atividades dos círculos de controle da qualidade, e seu principal papel ainda é motivar a participação de todos, o que leva as três empresas a realizarem premiações e/ou outros mecanismos para manter o nível de participação dos funcionários (índice monitorado inclusive pela área de recursos humanos). 


\section{Tabela 2 - Habilidades básicas e normas comportamentais (adaptada de Caffin \& Bessant, 1996).}

Habilidades
básicas

\author{
Normas \\ comportamentais
}

\author{
Exemplos de comportamentos vistos \\ na prática
}

Empresas

A $\quad$ B $\quad$ C

- Times de MC com potencial impacto sobre os objetivos da empresa quando avaliam soluções alternativas para os problemas

1. Indivíduos e grupos usam metas e objetivos estratégicos da organização para focar e priorizar suas atividades de melhoria

- Juntos, todos os membros dos departamentos envolvidos identificam e priorizam melhorias para irem ao encontro dos objetivos do departamento

- A freqüência, a localização e os resultados das melhorias são monitorados

2. Sistema de melhoria

(B) Gerenciar estrategicamente $\mathrm{o}$ desenvolvimento do sistema de melhoria contínua dentro das estruturas da organização contínua é continuamente monitorado e desenvolvido
- O sistema de MC é revisto periodicamente e ações são tomadas para melhorar sua eficiência - Treinamento relacionado à MC é estabelecido e melhorado depois de cada entrega

\section{A avaliação progressiva} assegura que a estrutura e a infra-estrutura da organização, bem como o sistema de melhoria contínua, consistentemente, reforcem e apóiem um ao outro

4. Gerentes de todos os níveis mostram compromisso ativo e liderança em relação à melhoria contínua

envolvimento sustentado em inovação incremental
(D) Trabalhar efetivamente ao longo das divisões internas e externas

(E) Garantir que a aprendizagem ocorra e seja capturada e compartilhada em todos os níveis

\section{Trabalho efetivo de} indivíduos e grupos por todos os níveis das divisões internas e externas

7. Aprendizagem por meio de experiências próprias e de outros, tanto positiva como negativa

8. A organização articula e desdobra a aprendizagem de indivíduos e grupos

(F) Articular, demonstrar e comunicar os valores da melhoria contínua
9. As pessoas "vivem" os valores da melhoria contínua
- A organização do trabalho foi reestruturada

para facilitar o trabalho em grupo

- Antes de uma fusão entre empresas um diretor estabelece seu impacto na atividade de $\mathrm{MC}$ e, como resultado, uma ação é tomada
- Gerentes sêniors promovem o treinamento em MC

- Gerentes liberam as pessoas da linha para participarem do trabalho de melhoria

- Pessoas de todos os níveis iniciam atividades de MC

- A medição do processo é amplamente utilizada

- Alto nível de cooperação entre departamentos e funções

- Pessoal da produção se reúne com os fornecedores-chave para discutir problemas e melhorias

- Problemas, assim como empreendimentos, são livremente discutidos com os colegas - Participação nas revisões de projetos divulgados e anunciados

- Uma ferramenta de matriz é usada para identificar outras áreas em que a melhoria pode ser aplicada

- Quando algo dá errado, as pessoas procuram a causa, em vez de um responsável - $\mathrm{O}$ pessoal administrativo acredita que fazer melhoria faz parte de seu trabalho
$\mathbf{X}$ 
Por outro lado, apesar de o objetivo ser motivacional, as atividades desenvolvidas por esses grupos de melhoria seguem uma orientação estratégica, que chega até eles por meio de quadros de gestão à vista e normalmente explicitam os indicadores de qualidade, produtividade, prazos e segurança. Apesar de as atividades serem relacionadas aos indicadores, não são inibidas outras propostas de melhoria.

Conforme citado, as três empresas possuem um programa de melhoria que trata de ações estratégicas. O uso dos programas Seis Sigma é um dos mecanismos utilizados, porém não o único, mesmo porque nessas empresas o programa ainda estava em seu início. Entretanto, a sistemática de analisar os objetivos estratégicos, relacionados ao desempenho atual e ao futuro, que inclui o desenvolvimento de novos projetos (produtos, clientes, redes de fornecimento e outros), envolve a participação gerencial e um grupo coordenador para acompanhar a implementação das ações definidas a partir da análise dos objetivos estratégicos da empresa.

Assim, parece que a prática de duas sistemáticas de melhoria contínua tem trazido benefícios para a produção, pois as empresas investigadas não pretendem eliminar nenhum dos programas. Ao contrário, buscam alguma solução que permita integrar as atividades desenvolvidas no âmbito das duas sistemáticas.

É importante destacar que, para as três empresas, considerando o lado pragmático, a melhoria contínua ocorre quando não há problema e se deseja melhorar os índices de desempenho.

Conclui-se, por intermédio da pesquisa, que ainda estão presentes atividades de melhoria locais e não necessariamente voltadas para a estratégia da empresa. Nos casos B e C, por exemplo, muitas iniciativas eram para melhoria de indicadores locais. Isso se torna comum em decorrência de problemas, como, por exemplo, o desdobramento ineficiente das estratégias. Porém, a continuidade dessas atividades de melhoria locais permitiu a participação do nível operacional.

As empresas estudadas apresentam sistemáticas de melhoria equivalentes, porém, que levam a comportamentos diferentes, o que pode ser explicado pelo fato de a ênfase estar em apenas observar oportunidades de melhoria focando na medida de desempenho associada. É razoável, então, supor que o fator diferenciador é o nível de prática das atividades de melhoria, considerando as atividades já desenvolvidas antes da QS 9000, ou seja, o tempo em que a empresa já pensava e realizava atividades de melhoria contínua da produção.

Os termos "habilidades" e "comportamentos" para melhoria contínua não eram de conhecimento das empresas. Dessa forma, podem até existir (o que foi verificado), porém, as empresas não têm consciência de sua presença no sistema, ou seja, não se pensa na habilidade como objetivo (realizar atividades de melhoria para alcançar a habilidade para melhoria contínua), o que pode prejudicar a gestão efetiva das atividades de melhoria contínua da produção. Seria importante a organização verificar primeiramente a competência que se quer ter e, assim, desenvolver práticas e comportamentos que suportassem e levassem a essas competências.

Além disso, não há preocupação em ter a habilidade (para resolver o problema, por exemplo) e sim sistemáticas e ferramentas. Entretanto, as pessoas nas empresas estão cada vez mais conscientes da importância dessas questões e, certamente, iniciativas voltadas para o aprimoramento de competências essenciais tendem a crescer.

$\mathrm{O}$ fato de as empresas apresentarem alguns comportamentos apenas diz que elas estão caminhando para adquirir a habilidade para melhoria contínua da produção. Mesmo que apresente todos os comportamentos, não se pode afirmar que a empresa tenha competência (aptidão) para melhoria contínua e que, portanto, esteja no nível máximo de maturidade para melhoria contínua. É importante deixar claro que nível de maturidade não significa "ter as habilidades". Uma vez tendo a habilidade, não é possível avaliar o nível de prática/maturidade, ou seja, é difícil avaliar o grau com que a habilidade se encontra em termos de prática.

O nível de maturidade mostra uma evolução da melhoria em termos de sistematização, 
comportamentos enraizados e atividades inerentes aos programas de melhoria contínua da produção que estejam implementadas e sejam praticadas. Não é possível afirmar no presente trabalho que a existência do comportamento garante que a empresa tenha a habilidade relacionada em sua forma integral e madura, ou seja, com diferentes níveis de capacitação. Encontrar o grau de capacitação em cada uma das habilidades requer acompanhamento de atividades e de comportamentos ao longo de um período maior, mas, em razão de sua especificidade, não foi avaliado neste trabalho.

A partir do momento em que a empresa tiver a consciência de que possui uma ou mais habilidades e, portanto, está em determinado nível de maturidade, além de ter por objetivo o próximo nível, precisará manter e melhorar os comportamentos que sustentam as habilidades já existentes em um contínuo processo de evolução. Assim, quando alcançar o último nível, não poderá estacionar só porque já apresenta todas as habilidades. Ela precisa constantemente rever seus processos para sempre melhorar, capacitando-se para novos desafios (dessa forma, chega-se à aptidão para melhoria contínua), caso contrário, o conjunto de competências essenciais alcançado poderá se tornar um conjunto de rigidez essencial. Afinal, a empresa pode ter a habilidade, porém, se acreditar que o comportamento ou a prática é um fato resolvido, pode desprezar oportunidades ou lições aprendidas que permitiriam desenvolver outros comportamentos que, certamente, seriam necessários para acompanhar a dinâmica das mudanças nas organizações.

Quanto aos programas de capacitação, estes são muito voltados para o treinamento em técnicas de melhoria, sem evidência de abordar questões associadas às habilidades. São necessárias abordagens que possam observar competências individuais e organizacionais, necessárias e existentes. De fato, os entrevistados evidenciaram a importância de um sistema de gestão que aborde essa questão.
Também foi identificada a necessidade de um grupo para analisar as informações que poderão ser colocadas em uma base de dados para melhoria contínua, o que pode significar, de certa forma, fazer gestão do conhecimento. Além disso, não há acompanhamento para verificar se as soluções atualmente implementadas ocorrem mais rapidamente que no passado, ou seja, se a aprendizagem realmente ocorre. Todas essas informações e dados teriam de ser lançados em um sistema para gerar uma base de conhecimento da empresa.

Em relação às habilidades, foram apontadas as observações mais relevantes. Apesar de terem sido identificadas na prática condutas associadas às normas, que por sua vez estão associadas às habilidades, a pesquisa não teve por objetivo acompanhar e compreender mais detalhadamente em que grau essas práticas efetivamente ocorrem na organização. Assumiu-se, então, a postura de analisar se o comportamento citado pela empresa poderia realmente ser associado à norma comportamental.

É importante observar que a terceira coluna da Tabela 2 apresenta uma lista de exemplos de comportamentos identificados na prática das empresas, correspondendo a cada uma das normas comportamentais associadas às habilidades básicas. Essas observações correspondem a comportamentos identificados por meio de pesquisa realizada por Caffyn \& Bessant (1996) e, da mesma forma, verificados nas empresas brasileiras estudadas. Já as três últimas colunas da Tabela 2, que correspondem a cada uma das empresas estudadas, identificadas por A, B e $\mathrm{C}$, mostram o que foi encontrado em cada caso em relação à presença de comportamentos praticados que pudessem ser relacionados às normas comportamentais e, conseqüentemente, às habilidades básicas para melhoria contínua.

Além de sintetizar parte dos resultados do estudo, a Tabela 1 pode servir de guia para realizar um diagnóstico preliminar em uma organização quanto à presença ou não de práticas associadas às normas comportamentais. Obviamente, a pre- 
sença de um ou mais comportamentos não revela se há ou não uma prática de gestão que considere essas questões, mas ajuda a chamar a atenção para a sua importância.

Acompanhando a coluna "empresas" da Tabela 2 , pode-se relatar alguns pontos importantes. Todas as empresas apontaram comportamentos associados às normas 1 e 2 . A priorização estratégica das empresas foi realmente notada. Esse pensamento se torna uma forte base para a sustentação e o alinhamento das atividades de melhoria de acordo com os objetivos e as metas da organização. O contínuo monitoramento também é essencial para sustentar as atividades de melhoria para que elas não ocorram ao acaso, como um evento isolado. É importante que as atividades estejam sempre direcionadas, considerando os objetivos e as metas da organização. Porém, a empresa $\mathrm{C}$ não apresentou comportamentos associados à norma 3 , relacionada à habilidade $\mathrm{B}$; realmente, o monitoramento e o acompanhamento da empresa ainda não estão efetivamente sistematizados para assegurar essa avaliação progressiva.

Todas as empresas apontaram comportamentos associados à norma 4. De fato, elas apresentam tal norma, porém em níveis de envolvimento e comprometimento diferentes. A empresa A não apontou comportamentos associados à norma 5 , relacionada à habilidade C, provavelmente por não possuir comprometimento ativo da alta administração. Afinal, quando a gerência é modificada, muda-se o foco das atividades de melhoria dentro da empresa, o que deixa o sistema sem consistência, fraco, sem continuidade, não levando a um comprometimento efetivo. Apesar de a empresa $\mathrm{C}$ apresentar comportamentos associados à norma 5, como a medição de processos, ela vai utilizála amplamente e de forma sistemática apenas no programa de indicadores estratégicos.

As empresas também apontaram comportamentos associados à norma 9 , evidenciando a presença da habilidade F. Na realidade, as pessoas não vivem os valores da melhoria con- tínua - a todo momento, todos estão preocupados com atividades de melhoria - como uma sistemática já enraizada nas rotinas e na cultura da empresa. O que realmente fazem é a prática. Dessa forma, apenas a habilidade A foi evidenciada em todas as empresas.

A empresa A não apontou comportamentos associados à norma 6, não apresentando, portanto, a habilidade $\mathrm{D}$, provavelmente pelo fato de a formação dos grupos ser fechada, ou seja, por já haver grupos predefinidos (times de produto, engenharia industrial e engenharia estatística). Apesar de evidenciar comportamentos relacionados a essa habilidade, a empresa $\mathrm{C}$ apresenta problemas com comunicação e cooperação entre departamentos, isto é explicado pelo fato de não haver retroalimenação efetiva para as atividades de melhoria, um sistema de feedback.

Apenas a empresa $\mathrm{C}$ não apontou comportamentos associados à norma comportamental 7 , não podendo evidenciar a presença da habilidade E por não apresentar sistemática e sistema efetivos para lançamento de experiências, tanto positivas quanto negativas. As outras empresas possuem comportamentos associados a essa norma, porém, vale lembrar que, apesar de possuírem sistemas estruturados para troca de informações e experiências, não lançam no sistema as experiências negativas, o que compromete o processo de aprendizagem.

Em relação à norma 8 , apenas a empresa $\mathrm{B}$ apontou comportamentos associados. Ou seja, foi a única que diz estabelecer uma coordenação das atividades de melhoria para que possam ser estendidas para toda a organização, podendo ser aplicadas em diferentes áreas.

Esses casos mostram que as empresas não estão conduzindo atividades de melhoria contínua da produção visando ao aumento de seu nível de maturidade (veja os cinco níveis de maturidade na Seção 2). Na realidade a empresa estrutura uma sistemática, desenvolve o treinamento em técnicas e ferramentas necessárias e, assim, considera-se habilitada a executar as atividades de melhoria. No entanto, a imple- 
mentação da sistemática e conseqüente prática rotineira de melhorias estratégicas ou locais e a solução de problemas sustentaram o desenvolvimento de comportamentos associados às habilidades. Dessa forma, é possível admitir que a sistematização adequada fundamenta o desenvolvimento das habilidades.

Diante dos dados encontrados nesta investigação, uma motivação aparece no sentido de direcionar o interesse para questões associadas à gestão das atividades de melhoria nas empresas. A concepção de um modelo conceitual e referencial para gestão das atividades de forma integrada e completa pode ser de grande valia; bem como um conjunto de questões pode ser detalhado para aprimorar o conhecimento sobre a prática da melhoria contínua nas organizações.

\section{Discussão de alguns aspectos importantes}

\section{Importância da melhoria contínua}

A partir do estudo realizado, torna-se relevante refletir sobre a importância do tema melhoria contínua da produção para as organizações que desejam se manter competitivas buscando sempre uma evolução consciente. Pode-se constatar que as empresas estão buscando alternativas para desenvolver projetos de melhoria mais intensamente. Observam-se a força dada pelas empresas aos projetos Seis Sigma e o esforço para envolver as gerências na definição de ações de melhoria estratégica. Atualmente, a qualidade não está mais associada apenas à produtividade, mas à vantagem competitiva, o que influencia as atividades de melhoria contínua e a forma como estas devem ser tratadas nas organizações. Pretende-se contribuir para o aumento da conscientização e motivação acerca da estruturação da melhoria contínua da produção como parte da estratégia do negócio, não como uma atividade isolada, destacando que a melhoria contínua pode ser uma abordagem com possibilidades muito mais amplas do que uma simples abordagem para aumento da produtividade. Assim, a melhoria contínua extrapola os limites de cumprimento de requisitos normativos, como os da QS 9000.

\section{Por que então melhorar continuamente?}

O perfeito não existe na prática. A motivação está em buscar o estado da arte, alcançando a cada dia um novo padrão de evolução. A essência da melhoria contínua está nessa busca rumo à evolução constante e consciente, superando os obstáculos, solucionando problemas, aprendendo com erros e acertos, ensinando, conhecendo, compartilhando cada conhecimento, contribuindo, assim, não somente para o crescimento pessoal e individual, mas também profissional e organizacional. O que se vê atualmente é o dinamismo de mercados, clientes, técnicas, metodologias, enfim, do ambiente.

Há um ritmo acelerado de mudanças. E, para acompanhar esse ambiente em constante transformação, torna-se essencial ter pensamentos e ações voltados para a melhoria contínua, enfim, desenvolver uma cultura com base nela. Sua prática facilita a criação de um ambiente de aprendizagem continuada, buscando o melhor uso do conhecimento existente na organização e potencializando a capacidade de criação de novos conhecimentos. Isso posiciona a melhoria contínua como uma prática útil nessa era do conhecimento.

As empresas podem apresentar algumas habilidades sem possuírem um modelo estruturado de gestão da melhoria contínua com base em competências.

Os resultados obtidos neste estudo mostram a preocupação das empresas em fazer uma boa gestão das atividades de melhoria contínua da produção. Provavelmente, foi a partir daí que elas conseguiram obter algumas habilidades. A razão pela qual não desenvolveram alguns dos comportamentos talvez se deva ao fato de não associarem a importância das condutas já existentes para sua sistemática de melhoria. É coerente, por exemplo, uma empresa apresentar algumas habilidades, e até mesmo todas as habilidades, sem nem mesmo 
ter consciência de sua existência. Afinal, o termo "habilidades básicas" foi retirado da boa prática das empresas. Inclusive, a elaboração da Tabela 2 teve por base um resultado misto entre prática e teoria. Dessa forma, a empresa que tem por objetivo as habilidades, conscientemente, pode facilitar o foco em como e $o$ que fazer para adquirir as competências essenciais para melhoria contínua da produção.

\section{Uma nova habilidade básica}

No decorrer da realização do trabalho, em relação às habilidades básicas para melhoria contínua, foi identificada outra habilidade que também pode ajudar as empresas a se capacitarem para gerenciar suas competências para melhoria contínua da produção. Essa habilidade pode ser chamada de habilidade de capturar, analisar a viabilidade, capacitar-se para implementar $e$ implementar a inovação tecnológica, ou seja, saber se é melhor desenvolver a melhoria incremental ou a inovação a todo o momento.

Daí a importância de conhecer o ambiente no qual a organização se insere para implementar a melhoria incremental ou a inovação, ou as duas, uma complementando a outra.

\section{Por que olhar para as competências?}

$\mathrm{O}$ foco em competências pode facilitar o como e $o$ que fazer para atingir os objetivos de forma mais direcionada, aplicando as ferramentas necessárias e facilitando, assim, a preparação para o futuro. $\mathrm{O}$ pensamento e as ações voltados para as competências podem ser formas de diferenciar a empresa, fazendo-a pensar além de técnicas e ferramentas, levando em consideração aspectos abstratos. A atenção às competências permite que as organizações aloquem esforços em aspectos mais relevantes para sua estratégia e sobrevivência. Elas podem se preparar melhor para desafios futuros e direcionar suas atividades de capacitação para alavancar conhecimentos úteis.

\section{Considerações finais}

Acredita-se que, com este artigo, a abordagem da melhoria contínua por meio de gestão de competências possa ser melhor compreendida e que as empresas praticantes possam usufruir de benefícios maiores que os experimentados com a abordagem "usual" (capacitação e uso de ferramentas para melhoria contínua - que é apenas um dos três grupos de competências propostos aqui: competências habilitadoras).

A importância da realização de um estudo de caso foi conhecer como as atividades de melhoria contínua da produção estavam sendo conduzidas, a fim de compará-las com as habilidades básicas para melhoria contínua da produção. Dessa forma, pôde-se diagnosticar a realidade das empresas e fazer algumas proposições que podem ser consideradas para estruturar uma abordagem mais ampla para melhoria contínua nas organizações.

Os casos estudados mostram que as competências estão, de um forma ou de outra, presentes na organização, mas nenhuma atividade é conduzida para geri-las. Assim, um modelo de gestão com base em competências para melhoria contínua poderia ser utilizado como guia referencial, permitindo ao gestor da melhoria contínua alavancar seu potencial, tanto na eficiência da realização de suas atividades quanto na eficácia em relação aos objetivos da organização.

Com base no ponto de vista deste trabalho olhando as competências para melhoria contínua -, as empresas apresentam algumas diferenças (veja Tabela 2), e as sugestões para que elas possam ampliar suas habilidades para realizar a melhoria contínua são no sentido de desenvolver ou aprimorar os comportamentos que as levariam a níveis superiores de maturidade da melhoria contínua.

Esse modelo pode servir de guia para a boa gestão de competências, visando à melhoria contínua da produção. Assim, é possível considerar aspectos técnicos e metodológicos juntamente 
com aspectos abstratos, estratificando-os de acordo com os três tipos de competência. Porém, cabe a cada empresa estruturar-se para que o uso de um modelo para gestão de competências possa se tornar uma rotina enraizada em sua cultura. Dessa forma, esse modelo facilitaria as empresas a passarem pelo processo de desenvolvimento das competências, um aprendizado que ficaria impregnado na cultura organizacional e permitiria a passagem pelos níveis de maturidade da melhoria contínua.

\section{Referências Bibliográficas}

BESSANT, J.; CAFFYN, S.; GALLAGHER, M. An evolutionary model of continuous improvement behavior. Technovation, v. 21, p. 67-77, 2001.

BESSANT, J.; CAFFYN, S.; GILBERT, J.; HARDING, R.; WEBB, S. Rediscovering continuous improvement. Technovation, v. 14, n. 1, p. 17-29, 1994.

BRANNEN, M. Y.; LIKER, J. K.; FRUIN, W. M. Recontextualisation and factory-factory knowledge transfer from Japan to the US: the case of NSK. In: LIKER, J. K.; FRUIN, W. M.; ADLER, P. (Eds.). Remade in America: transplating and transforming Japonese management systems. New York, NY: Oxford Press, 1998.

BRYMAN, A. Research method and organization studies. London: Unwin Hyman, 1989.

CAFFYN, S.; BESSANT, J. A capability-based model for continuous improvement. Proceedings of $3^{\text {th }}$ International Conference of the EUROMA. London, 1996.

CAFFIN, S.; BESSANT, J.; GALLENGHER, M. Development and testing of the generic model for continuous improvement: a report of the EPSRC sponsored CIRCA project. Center for Research in Innovation Management, Universty of Brighton, 1997.

DAVENPORT, T. H. Reengenharia de processos. Rio de Janeiro: Campus, 1994.

DAVENPORT, T. H.; PRUSAK, L. Conhecimento empresarial. Rio de Janeiro: Campus, 1998.

HARRISON, A. Continuous improvement: the trade off between self-management and discipline. Integrated Manufacturing System, v. 11, n. 3, p. 180-187, 2000.

HARRISON, A.; STOREY, J. New wave manufacturing strategies: operational, organizational and human dimensions. International Journal of Operations and Production Management, v. 16, n. 2, p. 6376, 1996.
IMAI, M. Gemba kaizen: a commonsense, low-cost approach to management. New York: McGrawHill, 1997.

JURAN, J. M. Managerial breakthrough: a new concept of the manager's job. New York: McGraw-Hill, 1969.

LEONARD-BARTON, D. Wellsprings of knowledge: building and sustaining the sources of innovation. Harvard Business School Press, 1995.

MERLI, G. EuroChallenge. The TQM Aproach to Capturing Global Markets. Oxford, Inglaterra: Information Press Ltd., 1993.

NONAKA, I.; TAKEUCHI, H. Criação de conhecimento na empresa. Rio de Janeiro: Campus, 1997.

RODRIGUES, A. M. Ações de melhoria na manufatura: investigação dos mecanismos de geração e abordagens utilizadas. Estudo de caso em empresas de autopeças. 1998. Dissertação (Mestrado) - Universidade Federal de São Carlos, UFSCar, São Carlos.

SALOMON, D. V. Como fazer uma monografia. 2. ed. São Paulo: Martins Fontes, 1991.

SHIBA, S.; GRAHAM, A.; WALDEN, D. TQM: quatro revoluções na gestão da qualidade. Porto Alegre: Artes Médicas, 1997.

SLACK, N.; CHAMBERS, S.; HARLAND, C.; HARRISON, A.; JOHNSTON, R. Administração da produção. São Paulo: Atlas, 1997.

UPTON, D. M. Mechanisms for building and sustaining operations improvement. European Management Journal, v. 14, n. 3, p. 215-228, 1996.

YIN, R. K. Case study research: design and methods. 2. ed. New Delhi: Sage, 1989. 


\title{
CORE COMPETENCE FOR CONTINUOUS IMPROVEMENT IN PRODUCTION OPERATIONS: CASE STUDY IN AUTOPARTS INDUSTRY COMPANIES
}

\begin{abstract}
This paper presents the results of a exploratory research realized in three ISO 9000 and QS 9000 certified companies of the autoparts industry to identify essential competences for continuous improvement in production operations. The main results are: companies have been practicing continuous improvement within a very good structure and in accordance with some specific systematics, developing training in techniques and tools, and by this way they consider theirself well able to realize improvement activities. However, they are not performing those activities to meet goals related to maturity level of continuous improvement, focusing in development of competences that are important to guarantee a long time evolution of continuous improvement in any company. Hence, this paper presents a discussion about the importance of managing continuous improvement based in competence management approach to facilitate organization to carry on the way to evolve in the level of continuous improvement maturity.
\end{abstract}

Key words: continuous improvement, knowledge management, operations management, quality management, competences development. 